\title{
Gastric ontogeny: clinical implications
}

\author{
Eric J Kelly, Simon J Newell
}

The delivery of a preterm infant offers a unique opportunity to look directly upon the process of ontogeny, while at the same time organ immaturity is the basis of the clinical problems which challenge neonatal medicine. In recent years our knowledge of foregut ontogeny has increased, together with an increased body of clinical experience, yet the nutritional management of the preterm infant remains a contentious area, with wide variations in clinical practice. The compelling evidence of the importance of early nutritional management on neurodevelopmental outcome now focuses the debate sharply. Closer knowledge of the development of functional maturity in the gut may allow more rapid and rational advances to be made. In this paper we discuss the embryology, the development of secretory and digestive function, and the maturation of gastro-oesophageal motor activity as a background to the clinical management of nutrition in the preterm infant.

\section{General embryology}

The human stomach develops from a fusiform swelling of the foregut at about 4 weeks' gestation. Originating in the neck, this swelling descends into the abdomen during the next eight weeks. Differential growth rates result initially in the formation of the greater and lesser curvatures, followed by a $90^{\circ}$ clockwise rotation of the stomach which occurs at 6 weeks' gestation. ${ }^{1}$ The stomach is initially lined by stratified ${ }^{2}$ or pseudostratified ${ }^{3}$ columnar epithelial cells which are later replaced by cuboidal cells. Gastric pits have developed in the epithelium by 14 weeks' gestation, and develop a mature glandular structure over the following weeks. Structural maturity is reached before the fetus becomes viable, and by 20 weeks' gestation the fetal stomach macroscopically and microscopically resembles that of the newborn infant at term.

Nerve fibres reach the gastric primordium at 5 weeks' gestation, four weeks before the first myoblasts are seen, and by 30 weeks' gestation both are morphologically and histologically mature. ${ }^{45}$

Regional Neonatal Unit, St James's University Hospital, Leeds LS9 7TF

E J Kelly

S J Newell

Correspondence to: Dr Newell. immune system and the initiation of digestion. Hydrogen ions are secreted by the parietal cells

\section{Acid secretion}

Gastric acid has many important functions in the human, including a role in the luminal located on the luminal aspect of the gastric mucosa by an energy dependent $\mathrm{H}^{+} / \mathrm{K}^{+}$ ATPase (proton pump). Acid secretion is under neural and hormonal control, principally vagal stimulation and local secretion of gastrin and histamine. These act either directly on the parietal cell or through enterochromataffin-like cells.

Differentiated glandular epithelial cells, which are structurally and histochemically identifiable as parietal cells, appear from 11 weeks' gestation. ${ }^{6}$ During early fetal life parietal cells are located in the body and antrum of the stomach, but by term only $20 \%$ of neonates have parietal cells in the antrum, similar to the proportion seen in adults. ${ }^{7}$ We have shown that from 13 weeks' gestation these parietal cells are functionally mature with the $\mathrm{H}^{+} / \mathrm{K}^{+}$ATPase in situ, ${ }^{8}$ and as early as 1929 Lucas-Keene and Hewer found hydrochloric acid in the fetal stomach from 19 weeks' gestation. ${ }^{9}$ It is not known how much acid the fetus produces in utero but we have recently demonstrated the secretion of gastric acid in even the most immature infants, from 24 weeks' gestation. In this study infants receiving intensive care were all found to be capable of producing and maintaining a gastric $\mathrm{pH}<2$ within the first days of life. ${ }^{10}$ The principal mechanisms controlling acid secretion in the preterm infant and the effects of factors such as enteral feeds are not known.

Gastric acid has both beneficial and detrimental effects in the immature newborn infant. Its presence acts as a barrier to the entry of micro-organisms into the small intestine, and one study has shown that infants given cimetidine had a higher incidence of necrotising enterocolitis than a control group. ${ }^{11}$ Gastric acid may therefore have a role in controlling gut microflora implicated in the aetiology of necrotising enterocolitis.

On the other hand, acid related disease may occur. Acid and pepsin are both present in the newborn, ${ }^{12}$ and mucosal damage occurs when there is imbalance between their harmful effects and mucosal protective mechanisms. Protection against acid-peptic damage is provided by a number of factors. It requires good gastric mucosal perfusion from the splanchnic circulation. Prostaglandins, notably $\mathrm{PGE}_{2}$ which is present in the gastric juice of sick preterm infants, ${ }^{13}$ have a number of actions which suggest their central role in mucosal protection. They stimulate mucus production and secretion of bicarbonate, 
inhibit acid secretion, and increase mucosal surface hydrophobicity. Epidermal growth factor (EGF) may also be cytoprotective. This acid stable peptide, present in large amounts in breast milk, ${ }^{14}$ produces inhibition of acid secretion in experimental animals. ${ }^{15}$ Receptors for EGF have now been demonstrated in the gastric mucosa of the fetus and the newborn. ${ }^{16}$

The preterm neonate is at high risk of acid-peptic disease. Sick preterm infants have been demonstrated to have a lower gastric $\mathrm{pH}$ than other preterm infants, increasing the risk of gastric bleeding. ${ }^{17}$ Mucosal resistance to acid peptic digestion may be reduced by poor gastric blood flow. Dexamethasone and indomethacin inhibit the production of cytoprotective prostaglandins, and tolazoline and morphine increase histamine concentrations. It is therefore not surprising that studies using endoscopy suggest a high incidence of mucosal lesions. ${ }^{18}$ Acid-peptic disease is most frequently restricted to superficial mucosal damage, but may produce more significant ulceration or haemorrhage. Gastric perforation is a rare but catastrophic event in sick, stressed, preterm infants, and carries a $50 \%$ mortality. It has been described in the fetus. ${ }^{19}$ In the neonate it may occur in association with dexamethasone $\mathrm{e}^{20}$ and tolazoline $\mathrm{e}^{21}$ treatment and there is a worrying theoretical risk with morphine. ${ }^{22}$

What strategy might therefore be adopted to best protect the preterm infant from acidpeptic disease? Circulatory support to avoid gastric hypoperfusion, and judicious use of agents likely to reduce mucosal resistance is prudent. When upper gastrointestinal bleeding occurs, or when the risk is high, as with the use of high dose dexamethasone, therapeutic or prophylactic intervention is justified. Milk feeds increase gastric $\mathrm{pH}$. In healthy preterm infants receiving three hourly formula feeds, buffering of intragastric $\mathrm{pH}>4$ lasts up to 90 minutes after a feed, ${ }^{23}$ and breast milk containing EGF, may confer further benefit. The histamine antagonist, ranitidine, is effective in the preterm infant. Intragastric acidity may be reduced to $\mathrm{pH}>4$, a value thought to prevent acid-peptic disease, with an intravenous infusion of ranitidine at 0.0625 $\mathrm{mg} / \mathrm{kg} /$ hour. ${ }^{24}$ The efficacy of $\mathrm{H}_{2}$ blockade in the prevention of mucosal lesions requires a controlled trial in the intensive care population. There are no data concerning omeprazole in the preterm infant. Sucralfate, which adheres to damaged mucous membrane and promotes local prostaglandin and mucus production, is effective in stress ulceration in adults, but may retard gastric emptying and has been reported to cause bezoar formation in a low birthweight infant. ${ }^{25}$ Misoprostol, a prostaglandin analogue, may have beneficial effects through reversal of the steroid induced disruption of cytoprotective mechanisms. Experience with misoprostol in the newborn is small, and long term use of prostaglandins to maintain patency of the ductus arteriosus in infants with congenital heart disease has been associated with gastric outlet obstruction. ${ }^{26}$
GASTRIN

Gastrin is produced by $G$ cells found within the antrum, pylorus, and duodenum. It is both a trophic hormone and a potent stimulant of gastric acid secretion. Immunohistochemical studies have demonstrated small numbers of $G$ cells between 12 and 18 weeks' gestation, ${ }^{27}$ becoming more numerous in the antrum as the density of parietal cells decreases. ${ }^{8}$ The mechanism linking gastrin and acid production in newborns is not understood but is thought to be different from that in adults. Newborn infants have significantly higher circulating concentrations of gastrin than adults, these high concentrations persist until at least 4 months of age. Under 3 months of age infants do not demonstrate the typical postprandial rise in gastrin seen in adults, ${ }^{28}$ and administration of the synthetic analogue pentagastrin produces no increase in gastric acid production. ${ }^{29}$ It is likely therefore that in the newborn, gastrin activity is maintained at maximal level.

\section{Motility}

Gastric and oesophageal motility are integrally linked, and it is worth noting the ontogenic coincidence of swallowing and mature lower oesophageal sphincter (LOS) function and small intestinal motility.

\section{OESOPHAGUS}

Interest here centres on the complex integrated function of swallowing and the lower oesophageal sphincter as a barrier against gastro-oesophageal reflux (GOR). Swallowing is first seen from 12-16 weeks, and has an important role in the regulation of liquor volume, as the fetus swallows $2-7 \mathrm{ml} /$ day initially, rising to $300-700 \mathrm{ml} /$ day at term. ${ }^{30}$ The role of swallowed liquor in the gastrointestinal ontogeny is not clear. Liquor is known to contain proteins, carbohydrates, and triglycerides which may be important as luminal nutrients. It clearly provides volume which may encourage the maturation of motility through secretion of enteric hormones, ${ }^{31}$ and interest recently has focused upon the large amount of growth factors present in the amniotic fluid. ${ }^{32} \mathrm{EGF}$, probably originating from the amniotic membranes, is present in high concentrations in liquor. ${ }^{16}$ In murine models, the administration of EGF antisera to the newborn is associated with significant retardation of small intestinal growth and maturity. ${ }^{33}$

Swallowing is a complex function, integrating the movement of a bolus from the mouth to the stomach with protection of the airway, inhibition of respiration, and appropriate relaxation of the oesophageal sphincters and the gastric fundus. In the newborn, nonnutritive sucking may be seen at a very early gestation but nutritive sucking and swallowing does not occur until 34 weeks' postconceptional age, even if infants are born earlier and have received intragastric milk feeds. This is unlike some other features of gut ontogeny, 
such as small intestinal motility which is increased when milk feeds are given, although mature patterns are not seen before 32 weeks. ${ }^{34}$

Little is known of the function of the upper oesophageal sphincter which may be detected manometrically from 32 weeks' gestation, 6-8 $\mathrm{cm}$ from the nares, and which shows the same response to a dry swallow in low birthweight and term infants. ${ }^{35}$ Coordinated motor activity in the body of the oesophagus is not present in the preterm, ${ }^{35}$ showing some of the features seen in older children with GOR. ${ }^{36}$ Oesophageal peristalsis matures with postnatal age and exposure to milk feeds. ${ }^{35}$

The LOS is the principal antireflux barrier. ${ }^{37}$ An effective LOS pressure must exceed intra-abdominal pressure in the fundus of the stomach. In the adult anatomical studies have now demonstrated the muscular equivalent of the high pressure zone, ${ }^{38}$ although the mechanisms of neuronal and hormonal control remain elusive. In the opossum, which is very immature at birth, an effective LOS pressure is present at birth, with continued maturation of muscle mass and function in the postnatal period. ${ }^{39}$ Similar observations have been made in the cat and dog. ${ }^{40}$

Studies in the human infant require careful attention to the physics of intraluminal pressure measurement which requires a continuously perfused, rapid response, low compliance manometric system. ${ }^{41}$ Details of system design were not given in a study which showed the absence of any effective sphincter pressure in the first six weeks of life in term or preterm infants. ${ }^{42}$ Newborn infants, however, do not reflux continuously, and a study of term infants at a mean age of 8 hours demonstrated effective LOS pressure equal or greater than those seen in older children. ${ }^{43}$ In the preterm infant effective LOS pressures rises from around $0.53 \mathrm{kPa}(4 \mathrm{~mm} \mathrm{Hg})$ before 28 weeks to $2.40 \mathrm{kPa}(18 \mathrm{~mm} \mathrm{Hg})$ at term. This rise in pressure is most clearly related to gestation at birth and postconceptional age rather than postnatal age or postnatal experience. ${ }^{44}$

GASTRO-OESOPHAGEAL REFLUX

GOR occurs when the LOS fails to prevent it. There is, however, no clear relationship between resting LOS pressure and GOR in the individual. ${ }^{45} 46$ This apparent paradox may be explained by motility studies. Reflux may occur in subjects with low sphincter pressure in association with a rise in intra-abdominal pressure. Alternatively it is seen during transient relaxation of the LOS, appropriately after a swallow, or inappropriately at other times. ${ }^{47}$ Similarly studies relating GOR to gastric emptying (see below) are at variance. It seems likely that the individual with good LOS function and rapid gastric emptying will be at low risk of GOR, while when either of these mechanisms is deficient, as occurs in the preterm infant, the risk of GOR will be increased.

In the preterm infant the combined effect of a poor antireflux barrier, immature oesophageal motility, and slow gastric emptying, make the risk of GOR high. Among preterm infants who have no symptoms to suggest reflux, $85 \%$ have a reflux index (percentage exposure time of the oesophagus to a $\mathrm{pH}<4$ ) greater than $1 \%$, with a mean reflux index of $4.5 \%{ }^{46}$ This is higher than seen in healthy term infant. ${ }^{48}$ Caffeine, which reduces LOS pressure, and physiotherapy, which increases intra-abdominal pressure, are both associated with increased reflux, ${ }^{46}$ while mechanical ventilation, which maintains a positive intrathoracic pressure, is associated with a diminution in the amount of reflux. ${ }^{49} 50$ There is now little doubt that reflux may be implicated in the pathogenesis of the problems of recurrent apnoea, 46 bronchopulmonary dysplasia, ${ }^{51}$ aspiration pneumonitis, ${ }^{52}$ and oesophagitis, ${ }^{53}$ and these issues have been discussed in detail elsewhere.

\section{GASTRIC EMPTYING}

In the active fetus between 26 weeks' gestation and term, liquor fills and empties from the stomach with a periodicity of around 45 minutes. ${ }^{54}$ In the early postnatal period adequate gastric emptying is essential for the introduction of enteral nutrition, and poor gastric emptying is common in the preterm infant, presenting as failure to 'tolerate' milk feeds. In the very low birthweight infant this problem may resolve quickly and spontaneously but may be protracted, and yet little is known about gastric emptying in these infants because of the methodological difficulties of studying small volume feeds, in infants receiving intensive care. ${ }^{55}$

Manometric studies in the preterm infant have shown poorly organised, non-rhythmic gastric pressure waves following on from oesophageal peristalsis. ${ }^{35}$ Pressure in the fundus $^{44}$ and antrum ${ }^{34}$ rises with increasing postconceptional age. Gastric emptying has been measured in the preterm infant established on milk feeds. Half emptying times for breast milk have been estimated between 20 and 40 minutes. ${ }^{55-57}$ This is slower than the term infant and follows a biphasic curve, with an initial fast phase which is less obvious when artificial formula is used. ${ }^{56} \mathrm{~A}$ number of factors have been shown to have an effect upon gastric emptying. The stomach empties less quickly with increasing energy density, ${ }^{58}$ higher fat and long chain triglyceride content, ${ }^{59}$ and greater dextrose concentration, ${ }^{60}$ and is modified by position and postnatal disease. ${ }^{61}$ Emptying is more rapid when breast milk is used rather than formula, ${ }^{5657}$ glucose polymers rather than dextrose, and medium chain rather than long chain triglycerides. ${ }^{59}$ Osmolality, ${ }^{62}$ temperature of the feed, phototherapy, ${ }^{63}$ and non-nutritive sucking ${ }^{64}$ have been studied without an apparent affect upon emptying.

If the relationship between gastric emptying and gestation or the effects of early introduction of milk feeds are to be explored a technique capable of repeated measurements of emptying of small volume feeds without 
disturbance of the infant in intensive care is required. Radiographic and isotope techniques have obvious drawbacks. Measurement of residual volume can only be done once during each feed and assumes that the stomach can be emptied through an intragastric tube. Dye dilution techniques have been refined and allow accurate repeated measurement of intragastric volume. ${ }^{64}$ Dye, however, must be instilled and mixed with gastric contents making this technique less suitable for the study of small volume feeds. We have recently used ultrasound to make repeated assessments of antral cross sectional area during a feed, ${ }^{55}$ allowing the study of feeds down to $4 \mathrm{ml}$ volume, with minimal disturbance to the infant. This method has been used to demonstrate marked difference in gastric emptying of breast milk and formula. ${ }^{57}$

Future work will need to look at the effects of maturity, postnatal age, and the effects of feeding upon gastric emptying. Current knowledge concerning the physiological control of the maturation of gastric emptying is poor, and the relationship between GOR and gastric emptying needs elucidation as the current evidence in this area is conflicting. The modulation of gastric emptying through refinements of the composition of milk and timing and method of feed administration requires exploration. Cisapride, a prokinetic agent, has been used in infants in a dose range of $0 \cdot 1-0.3 \mathrm{mg} / \mathrm{kg} /$ dose, eight hourly, to accelerate gastric emptying and for the control of GOR. One uncontrolled study in preterm infants has demonstrated improved gastric emptying ${ }^{65}$ but double blind controlled studies are needed to determine its potentially beneficial role.

In the term infant, persistent clinical problems as a result of poor gastric emptying are rare. Infants with congenital gut anomalies, notably gastroschisis, on the other hand may have protracted problems. The origin of these problems is unclear. It may relate to the abnormal intrauterine environment of the gut, or perinatal and postnatal trauma. The association between chronic intestinal pseudoobstruction and the persistence of motility disorders in infants who have had malrotation may allow inference of a primary motility disorder which may have led to the congenital abnormality. ${ }^{66}$

\section{Digestive functions}

Digestion is initiated within the stomach, with the secretion of both acid and pepsin. A variety of pepsins are released in response to antral distension through complex neural and hormonal mechanisms. Pepsinogens have been demonstrated immunohistochemically, in the chief cells from 19-21 weeks' gestation, 67 and peptic activity is present in the stomach in the very low birthweight infant. ${ }^{68}$ Jejunal feeding, however, is associated with normal gastrointestinal absorption and function, ${ }^{69}$ and the contribution of peptic activity to protein digestion may be small.

The initial hydrolysis of dietary triglycerides begins in the stomach through the action of acid stable lipase. Gastric lipase appears from the 11 th week of development and is secreted in the fundal region of the stomach. ${ }^{70}$ Acid stable lipase activity is of gastric origin, although the part played by lingual and breast milk lipases in initial digestion is unknown. Amniotic fluid contains triglycerides (120 $\mathrm{mg} / \mathrm{l}),{ }^{71}$ and gastric digestion of lipids may begin during fetal life. In a study of 350 preterm infants lipolytic activity in gastric aspirates was found to reach peak activity at 30-32 weeks' gestation. ${ }^{72}$

\section{INTRINSIC FACTOR}

Intrinsic factor is a small glycoprotein synthesised and secreted by the parietal cells under the same neural and hormonal mechanisms involved in modulating acid secretion. It binds to the cobalamin present in vitamin B-12 and is absorbed intact in the terminal ileum. Immunohistochemical ${ }^{8}$ and autoradiographic ${ }^{73}$ techniques have noted that intrinsic factor is present in parietal cells from the end of the first trimester. There are no clinical studies looking at the secretion of intrinsic factor or absorption of vitamin B-12 in the immature infant.

\section{Conclusion}

The upper gut shows considerable structural and functional maturity by the end of the second trimester, but problems related to its function are common in the very low birthweight infant. Awareness of prenatal factors, the influence of intrauterine nutrition, and of elements of postnatal care that may affect gastrointestinal ontogeny is essential for future advances in the use of enteral feeding. The observation that LOS maturation is not modified by postnatal factors, while gastric emptying clearly is, is hard to explain. Our ability to induce gut maturity and the use of milk feeds, not only as a source of nutrition, but also as a method of promoting maturation, needs further exploration.

Gastric acid is produced by the preterm infant and endoscopy is beginning to provide data which suggest that we may have been under-recognising acid-peptic disease. However, there is insufficient evidence to support the suggestion that all undergoing intensive care should receive acid blocking agents. Currently reduction of gastric acid production may be justified in infants at high risk of acid-peptic mucosal damage. $\mathrm{H}_{2}$ blockade with ranitidine is effective in increasing gastric $\mathrm{pH}$, but omeprazole or cytoprotective prostaglandin analogues may be used in the future.

Poor LOS function, slow gastric emptying, and immature patterns of gastro-oesophageal motility make GOR common. The role of GOR in the pathogenesis of respiratory problems is now well established. GOR has a natural history of resolution in most infants, but when necessary, treatment may be effective, and will probably increasingly 
include the use of cisapride. Slow gastric emptying may increase reflux, but most frequently presents with poor 'toleration' of feeds. Studies involving manipulation of feed composition and timing may well be helpful in these infants, allowing better prediction of a baby's ability to tolerate feeds, and providing guidance in the choice of milk and mode of administration. The study of gastric emptying exemplifies well how research into the natural history of ontogeny, and the effects of intrauterine and postnatal environment upon that process, may, in the future, allow the formation of a rational basis for the nutritional management of the preterm infant.

1 Arey LB. Developmental anatomy. Philadelphia: WB Saunders, 1974: 245-62.

2 Hayward AF. The ultrastructure of the developing gastric parietal cells in the foetal rabbit. F Anat 1967; 101: 69-83.

3 Menzies PL. Observations on the development of certain cell types in the fundic region of the rabbit stomach. Quarterly fournal of Microscope Science 1964; 105: 449-62.

4 Bremner G. Studies on the pyloric muscle. $S$ Afr $\mathcal{f}$ Surg 1968; 6: 79-85.

5 Deren JS. Development of structure and function in the fetal and newborn stomach. Am f Clin Nutr 1971; 24: 144-59.

6 Normura Y. On the submicroscopic morphogenesis of parietal cells in the gastric gland of the human foetus. Zeitschrift für Anatomie und Entwicklungsgeschichte (Berlin) 1966; 125: 316-22.

7 Naik KS, Lagopoulos M, Primrose JN. Distribution of antral G-cells in relation to the parietal cells of the stomach and anatomical boundaries. Clinical Anatomy 1990; 3: 17-24.

8 Kelly EJ, Lagopoulos $\dot{M}$, Primrose $\mathrm{N}$. Immunocytochemical localisation of parietal cells and G-cells
within the developing human stomach. Gut 1993; 34: within the

9 Lucas-Keene MF, Hewer EE. Digestive enzymes in the human foetus. Lancet 1929; i: 767-9.

10 Kelly EJ, Newell SJ, Brownlee KG, Primrose JN, Dear PRF. Gastric acid secretion in preterm infants. Early Hum Dev 1993; 35: 215-20.

11 Udall JN. Gastrointestinal host defence and necrotizing enterocolitis. F Pediatr 1990; 117: S33-44.

12 Agunod M, Yamaguchi N, Lopez R, Luhby AL, Glass GBJ. Correlative study of hydrochloric acid, pepsin and intrinsic factor secretion in newborns and infants. American fournal of Digestive Diseases 1969; 14: 400-14.

13 Marino LR, Blumer JL, Halprin TC. Prostaglandin $\mathrm{E}_{2}$ concentrations in gastric secretions of critically ill, full term, and premature infants. Pediatr Res 1983; 17: 669-71.

14 Reed LC, Upton FM, Francis GL, et al. Changes in the growth promoting activity of human milk during lactation. Pediatr Res 1984; 18: 133-9.

15 Konturek SJ, Brzozowski T, Konturek PK, Majka J, Dembinski A. Role of salivary glands and epidermal growth factor (EGF) in gastric secretion and mucosal integrity in rats exposed to stress. Regul Pept 1991; 32: 203-15.

16 Kelly EJ, Newell SJ, Brownlee KG, Primrose JN. The ontogenic role of EGF and TGF alpha in the developing human stomach. Gut 1993; 34 (suppl 4): S31.

17 Sankaman K, Hayton S, Duff E, Waygood B. Time-wise sequential analysis of gastric aspirate for occult blood and pH in sick preterm infants. Clin Invest Med 1984; 7: 115-8.

18 Maki M, Ruuska T, Kuusela A-L, et al. High prevalence of asymptomatic esophageal and gastric lesions in preterm infants in intensive care. Crit Care Med 1993; 21: 1863-7.

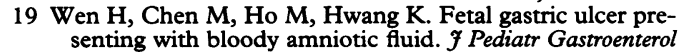
Nutr 1992; 15: 455-7.

$20 \mathrm{Ng}$ PC, Brownlee KG, Dear PRF. Gastroduodenal perforation in preterm babies treated with dexamethasone for 1164-6.

21 Butt W, Auldist A, McDougall P, Duncan A. Duodenal ulceration: a complication of tolazaline therapy. Australian Paediatric fournal 1986; 22: 221-3.

22 Treuren BC, Galletly DC, Robinson BJ, Short TG, Ure RW. The influence of $H_{1}$ and $H_{2}$ receptor antagonists, RW. The influence of $H_{1}$ and $H_{2}$ receptor antagonists, terfenadine and ranitidine, on the hypertensive and gastric $\mathrm{pH}$ effects of the histamine releasing drugs mon

23 Sondheimer JM, Clark DA, Gervaise EP. Continuous gastric pH measurement in young and older preterm gastric pH measurement in young and older preterm $\Im$ Pediatr Gastroenterol Nutr 1985; 4: 352-5.

24 Kelly EJ, Chatfield SL, Brownlee KG, Primrose JN, Newell SJ, Dear PRF. The effect of intravenous ranitidine on the intragastric $\mathrm{pH}$ of preterm infants receiving dexamethasome. Arch Dis Child 1993; 69: 37-9.
25 Tang $T$, Yeung $C$. Intestinal obstruction and perforation ollowing sucralfate administration in a very low birth weight infant. $\mathcal{F}$ Perinat Med 1992; 20: 317-21.

26 Peled N, Dagan O, Babyn P, et al. Gastric-outlet obstruction induced by prostaglandin therapy in neonates. $N$ Engl f Med 1992; 327: 505-10.

27 Grasso S, Buffa R, Martino E, Bartalena L, Curzio M, Salomone E. Gastrin (G) cells are the cellular site of the gastric thyrotropin-releasing hormone in human fetuses and newborns. A chromatographic, radioimmunulogical, and immunocytochemical study. $\mathcal{f}$ Clin Endocrinol Metab 1992; 74: 1421-6.

28 Moazam F, Kirby WJ, Rogers BM, McGuigan JE. Physiology of serum gastrin production in neonates and Physiology of serum gastrin production
infants. Ann Surg 1984; 199: 389-92.

29 Euler AR, Bryne WJ, Meis PJ, Leake RD, Ament ME. Basal and pentagastrin stimulated acid secretion in newborn human infants. Pediatr Res 1983; 13: 36-7.

30 Pritchard JA. Fetal swallowing and amniotic fluid volume. Obstet Gynecol 1966; 28: 606-10.

31 Lucas A, Bloom SR, Aynsley-Green A. Metabolic and endocrine events at the time of the first feed of human milk in preterm and term infants. Arch Dis Child 1978; 53: 731-6.

32 Weaver LT, Walker WA. Epidermal growth factor and the developing human gut. Gastroenterology 1988; 94: $845-7$

33 Zschiesche W. Retardation of growth and epithelial differentiation in suckling mice by anti-EGF antisera. Biomed Biochim Acta 1989; 48: 103-9.

34 Bisset WM, Watt JB, Rivers RPA, Milla PJ. The ontogeny of small intestinal fasting motor activity in the human infant. Gut 1988; 29: 483-8.

35 Gryboski JD. The swallowing mechanism of the neonate I: esophageal and gastric motility. Pediatrics 1965; 35: 445-52.

36 Cucchiara S, Staiano A, Di Lorenzo C, et al. Esophageal motor abnormalities in children with gastroesophageal reflux and peptic disease. $\mathcal{f}$ Pediatr 1986; 108: 907-10.

37 Newell SJ. The lower oesophageal sphincter in the preterm infant. In: Milla PJ, ed. Disorders of gastro-intestinal motility in childhood. Chichester: John Wiley, 1988: 39-50.

38 Liebermann-Meffert D, Allgower M, Schmid P, Blum AL. Muscular equivalent of the lower esophageal sphincter. Gastroenterology 1979; 76: 31-8.

39 Cohen S. Developmental characteristics of lower esophageal sphincter function: a possible mechanism for infantile chalasia. Gastroenterology 1974; 67: 252-8.

40 Spedale SB, Weisbrodt NW, Morriss JR. Ontogenic studies of gastro-intestinal function II: lower esophageal sphincter maturation in neonatal beagle puppies. Pediatr Res 1982; 16: 851-5.

41 Weihrauch TR. The physics of intraluminal pressure recording. Oesophageal manometry: methods and clinical practice. Baltimore-Munich: Urban and Schwarzenberg, 1981: $20-63$.

42 Boix-Ochoa J, Canals J. Maturation of the lower esophagus. 7 Pediatr Surg 1976; 11: 749-56.

43 Moroz SP, Beiko P. Relationship between lower oesophageal sphincter pressure and serum gastrin concentration in the newborn infant. $f$ Pediatr 1981; 99: 725-8.

44 Newell SJ, Sarkar PK, Durbin GM, Booth IW, McNeish AS. Maturation of the lower oesophageal sphincter in the preterm baby. Gut 1988; 29: 167-72.

45 Euler AR, Byrne WJ. Twenty four hour esophageal intraluminal pH probe testing: a comparative analysis. Gastroenterology 1981; 80: 957-61.

46 Newell SJ, Booth IW, Morgan MEI, Durbin GM, McNeish AS. Gastro-oesophageal reflux in preterm infants. Arch Dis Child 1989; 64: 780-6.

47 Brueton MJ, Clarke GS, Sandhu BK. Gastro-esophageal reflux in infancy. In: Milla PJ, ed. Disorders of gastro-intestinal motility in childhood. Chichester: John Wiley, 1988: $53-64$

48 Vandenplas $Y$, Goyvaerts $H$, Helven $R$, Sacre $L$. Gastroesophageal reflux, as measured by 24-hour $\mathrm{pH}$ monitoring, in 509 healthy infants screened for risk of sudden infant death syndrome. Pediatrics 1991; 88: 834-40.

49 Pradeaux L, Boggio V, Gouyon JB. Gastro-oesophageal reflux in mechanically ventilated preterm infants. Arch Dis Child 1991; 66: 793-6.

50 Newell SJ, Morgan MEI, Durbin GM, Booth IW, McNeish AS. Does mechanical ventilation precipitate gastro1989; 64: 1352-5.

51 Hrabovsky EE, Mullett MD. Gastroesophageal reflux in the premature infant. $\mathcal{F}$ Pediatr Surg 1986; 21 : 583-7.

52 Wharton BA, Bower BD. Immediate or later feeding for premature babies? A controlled trial. Lancet 1965; ii: 969-72.

53 Anand KJS. Gastric lesions in neonates: effects of stress? Crit Care Med 1993; 21: 1817-9.

54 Devane SP, Soothill PW, Candy DCA. Temporal changes in gastric volume in the human fetus in late pregnancy. Earl Hum Dev 1993, 33: 109-16.

55 Newell SJ, Chapman S, Booth IW. Ultrasonic assessment of gastric emptying in the preterm infant. Arch Dis Child 1993; 69: 32-6.

56 Cavell B. Reservoir and emptying function in the stomach of the premature infant. Acta Paediatrica Scandinavica 1982; 296: $60-1$.

57 Ewer AK, Durbin GM, Morgan MEI, Booth IW. Gastric emptying in preterm infants: a comparison of breast milk and formula. Arch Dis Child 1994; 71: F24-7. 
58 Siegel M, Lebebthal E, Krantz B. Effect of caloric density on gastric emptying in premature infants. $\mathcal{f}$ Pediatr 1984 104: $118-22$.

59 Siegel M, Krantz B, Lebenthal E. Effect of fat and carbohy drate composition on the gastric emptying of isocaloric feedings in premature infants. Gastroenterology 1985; 89: 785-90.

60 Husband J, Husband P. Gastric emptying of water and glucose solutions in the newborn. Lancet 1969; ii: and glucose

$61 \mathrm{Yu} \mathrm{VYH}$. Effect of body position on gastric emptying in the neonate. Arch Dis Child 1975; 50: 500-4.

62 Siegel M, Lebenthal E, Topper W. Gastric emptying in prematures of isocaloric feedings with different osmolalities. Pediatr Res 1982; 16: 141-7.

63 Blumenthal I, Lealman GT. Effect of feed temperature and phototherapy on gastric emptying in the neonate. Arch Dis phototherapy on gastric

64 Szabo JS, Hillemeier AC, Oh W. Effect of non-nutritive and nutritive suck on gastric emptying in premature infants. $\mathcal{f}$ Pediatr Gastroenterol Nutr 1985; 4: 348-51

65 Melis K, Janssens G. Long-term use of cisapride (Prepulsid) in premature neonates. Acta Gastroenterol Belg 1990; 53: 372-5.

66 Devane SP, Coombs RC, Smith VV, et al. Persistent gastro- intestinal symptoms after correction of malrotation. Arch Dis Child 1992; 67: 218-21.

67 Reid WA, McGechaen K, Branch T, Gray HDA, Thompson WD, Kay J. Immunolocalisation of aspartic proteinases in the developing human stomach. $\mathcal{f} D e v$ Physiol 1989; 11: 299-303.

68 Adamson I, Esangbedo A, Okolo AA, Omene JA. Pepsin and its multiple forms in early life. Biol Neonate 1988; 53: 267-73

69 Macdonald PD, Skeoch $\mathrm{CH}$, Carse $\mathrm{H}$, et al. Randomised trial of continuous nasogastric, bolus nasogastric, and ther $1400 \mathrm{~g}$. Arch Dis Child 1992; 67: 429-31. 70 Sarles J. Arch Dis Child Vastric lipase: ontogeny and variations in children. Acta Paediatr 1992; 81: $511-3$

71 Codaccioni X, Lecountour X, Delecour M, Biserta G. Physiologie du liquide amniotique. Encyclopédie Médicale t Chirugicale (Paris) Obstetrique 1985; 5006 A10,6

72 Lee PC, Borysewicz R, Sturve M, Raab K, Werlin SL. Development of lipolytic activity in gastric aspirates from premature infants. $\mathcal{F}$ Pediatr Gastroenterol Nutr 1993; 17: 291-7.

73 Hoedemaker PJ, Abels J, Watchers JJ, Arends A, Nieweg H. Further investigations about the site of production of gastric intrinsic factor. Lab Invest 1966; 15: 1163-73. 